\title{
Formigas urbanas da cidade de Xanxerê, Santa Catarina, Brasil
}

\author{
Samanta Iop ${ }^{1 *}$ \\ Vinícius Matheus Caldart ${ }^{1}$ \\ Junir Antonio Lutinski² \\ Flávio Roberto Mello Garcia ${ }^{3}$ \\ ${ }^{1} \mathrm{PPG}$ em Biodiversidade Animal. Departamento de Biologia \\ Centro de Ciências Naturais e Exatas, Universidade Federal de Santa Maria \\ Av. Roraima s/n ${ }^{\circ}$ CEP 97105-900, sala 1140, Santa Maria - RS, Brasil \\ ${ }^{2}$ Universidade Comunitária Regional de Chapecó - UNOCHAPECÓ \\ Caixa Postal 747, CEP 89809-000, Chapecó - SC, Brasil \\ ${ }^{3}$ Universidade Federal de Pelotas, Instituto de Biologia \\ Departamento de Zoologia e Genética, Laboratório de Ecologia de Insetos \\ Caixa-Postal: 354, CEP 96010-900, Pelotas - RS, Brasil \\ flavio.garcia@pq.cnpq.br \\ *Autor para correspondência \\ samantaiop@yahoo.com.br
}

Submetido em 25/06/2008

Aceito para publicação em 17/12/2008

\section{Resumo}

A mirmecofauna de Santa Catarina vem sendo inventariada há mais de 60 anos; no entanto, pesquisas com formigas associadas a ambientes urbanos só começaram a ser realizadas na última década no Estado. Devido à carência de pesquisas nesta área, o presente trabalho objetivou conhecer a mirmecofauna urbana de Xanxerê, oeste de Santa Catarina. As coletas foram realizadas no período de janeiro a dezembro de 2006, utilizando-se de iscas à base de sardinha e coletas manuais. A partir do número de registros das espécies realizou-se a caracterização da fauna através dos índices de diversidade (Shannon \& Wiener - H') e de riqueza (Jackknife 1 e Bootstrap). Foram identificadas 67 espécies, distribuídas em 21 gêneros, 13 tribos e seis subfamílias: Myrmicinae (33), Formicinae (17), Dolichoderinae (10), Ponerinae (4), Pseudomyrmecinae (2) e Ectatomminae (1). O índice de diversidade encontrado foi de 3,17 . Os índices de riqueza encontrados em residências, estabelecimentos comerciais e métodos de captura mostram que a riqueza de espécies observada foi satisfatória, devido à aproximação da estabilidade apresentada nas curvas de estimativa de riqueza. Constatou-se a presença de espécies típicas de ambientes perturbados e de espécies que causam incômodo quando associadas ao homem, bem como a presença de especialistas de habitat e associadas à vegetação.

Unitermos: Formicidae, riqueza, áreas urbanas, infestação

\section{Abstract}

Urban ants of Xanxerê town, Santa Catarina, Brazil. The Myrmecofauna of Santa Catarina State has been studied for more than sixty years; however, studies on urban ant species only began last decade in the state. This study was carried out due to the need of new research in this field for the purpose of elucidating the urban myrmecofauna of Xanxerê, in the west of Santa Catarina. Samples were taken from January to December of 2006 , 
using sardine baits and direct sampling. The sampled urban communities were characterized by high species diversity (Shannon \& Wiener - H') and species richness (Jackknife 1 and Bootstrap) values. These communities yielded a total of 67 ant species, distributed in 21 genera, 13 tribes and six subfamilies: Myrmicinae (33), Formicinae (17), Dolichoderinae (10), Ponerinae (4), Pseudomyrmecinae (2) and Ectatomminae (1). The species diversity was 3.17 . The observed ant species richness in houses, commercial establishments and samples showed that the sampling protocol was satisfactory, due to the stability of approximation to the species accumulation curves of estimated species richness. Typical species which are common in areas of stress and also species that cause harm to man were found, as well as habitat specialists and those associated with the vegetation.

Key words: Formicidae, richness, urban areas, infestation

\section{Introdução}

São conhecidas aproximadamente 12.461 espécies de formigas no mundo para uma fauna estimada em 20.000 (Agosti e Johnson, 2008). Para o Brasil são conhecidas aproximadamente 2.000 espécies de formigas (Bueno e Campos-Farinha, 1999). Para o Estado de Santa Catarina foram registradas 342 espécies (Silva, 1999); na região oeste do Estado são conhecidas 184 espécies, dados obtidos a partir de coletas não sistematizadas empregadas pelo naturalista Fritz Plaumann por mais de 60 anos nas cidades de Chapecó, Concórdia, Ponte Serrada, Seara e Xaxim (Silva e Silvestre, 2000).

Estudos conduzidos no interior de residências mostram que a riqueza de formigas é baixa, devido aos limitados recursos disponíveis que não atendem as exigências da maioria das espécies de formigas. Piva e Campos-Farinha (1999) registraram 18 espécies em um bairro da cidade de São Paulo. Essa baixa riqueza pode estar relacionada ao hábito de nidificação e forrageamento de cada espécie, já que a disponibilidade de nichos é menor no interior de residências. Por outro lado, coletas realizadas em todo o perímetro urbano registram uma riqueza maior de formicídeos devido à maior disponibilidade de nichos, como é o caso da pesquisa realizada por Farneda et al. (2007) no perímetro urbano da cidade de Pinhalzinho, Santa Catarina, onde foram registradas 60 espécies.

Estudos sobre a ocorrência de formigas em ambientes urbanos vêm sendo realizados desde a década de 1980, evidenciando mais de duas dezenas de espécies que podem ser consideradas pragas neste meio, apresentando sérios danos onde são encontradas associadas ao homem, como em residências, estabelecimentos comerciais, hospitais, fábricas, biotérios e em outros locais (CamposFarinha et al., 2007).

Geralmente, os danos causados pelas espécies que invadem residências incluem o incômodo pela sua presença em cozinhas, despensas e banheiros (Bueno e Campos-Farinha, 1999), e a nidificação em aparelhos eletrônicos como geladeiras, televisões, vídeos, aparelhos de som, computadores entre outros (Silva e Loeck, 1999). Em ambientes hospitalares, os problemas são ainda maiores, uma vez que algumas espécies atuam como vetores potenciais de organismos patogênicos que estão comumente associados à infecções hospitalares (Zarzuela et al., 2002; Fernández, 2003; Costa et al., 2006). Levantamentos sobre a incidência de formigas em ambientes hospitalares no Brasil também tiveram início na década de 80 em São Paulo, quando foram registradas 14 espécies (Fowler et al., 1993). O primeiro trabalho inventariando a presença de formigas em hospitais no Estado de Santa Catarina foi realizado por Lise et al. (2006), onde foram coletadas sete espécies, associadas a 19 espécies de bactérias causadoras de infecções hospitalares.

Todavia, apesar dos estudos já realizados no oeste de Santa Catarina, poucos têm explorado à mirmecofauna urbana. Deste modo, o principal objetivo do presente trabalho é descrever as espécies associadas ao ambiente urbano na cidade de Xanxerê.

\section{Material e Métodos}

As coletas foram realizadas na cidade de Xanxerê (26 51'17.29'S, 52 24'12.30”O), localizada no oeste do Estado de Santa Catarina, a qual apresenta uma população estimada em 40.222 habitantes (IBGE, 2008). 
O inventariamento da mirmecofauna foi realizado através de coletas quinzenais no período de janeiro a dezembro de 2006, totalizando 24 coletas. Para tal, o perímetro urbano foi dividido em quatro áreas de tamanho semelhante para viabilizar uma maior dispersão dos pontos amostrais (A1, A2, A3 e A4), conforme descrição a seguir:

Área 1: está localizada na porção sudoeste da cidade. Apresenta alguns terrenos baldios com vegetação rasteira e arbustiva considerável e abrange em quase toda sua extensão áreas residenciais, sendo que apenas o centro concentra estabelecimentos comerciais. Está localizada próxima à BR-282 e a várias indústrias. Essa área apresenta a maioria das ruas pavimentada e abriga um pequeno remanescente de vegetação que faz contato com a área 4.

Área 2: está localizada na porção noroeste da cidade, apresentando muitos terrenos baldios com vegetação rasteira. A área caracteriza-se por ser predominantemente residencial, sendo que uma pequena porção próxima ao centro da cidade possui estabelecimentos comerciais. A grande maioria das ruas não é pavimentada.

Área 3: localizada na porção nordeste da cidade, apresenta terrenos baldios com vegetação rasteira e arbustiva considerável. Trata-se de uma região predominantemente residencial, onde a maioria das ruas é pavimentada.

Área 4: localizada na porção sudeste da cidade, apresenta grande número de terrenos baldios com considerável vegetação arbustiva. Apresenta grande parte da vegetação com representante de plantas nativas e é nessa área que está situada a única praça da cidade. Está localizada próxima à BR-282, onde se encontra um remanescente de vegetação que faz contato com a área 1. A maioria das ruas é pavimentada.

Todas as áreas fazem contato em algum ponto com o centro da cidade. $\mathrm{O}$ centro e as áreas próximas à BR-282 possuem maior fluxo de indivíduos dentre as áreas amostradas. Outro fato relevante é a existência do rio Xanxerê, o qual corta o centro da cidade passando entre as áreas 1,2, e 4. As áreas amostradas são bastante homogêneas quanto à urbanização e à vegetação rasteira, fato que está relacionado à pequena área urbana da cidade e ao baixo número de habitantes que a cidade concentra.

Em cada área foram realizadas duas coletas mensais em residências e estabelecimentos comerciais, sendo que, em cada coleta, foram escolhidos aleatoriamente diferentes pontos amostrais, nunca repetindo as coletas em um mesmo imóvel.

Foram utilizadas iscas à base de sardinha em óleo e coletas manuais como métodos de captura. Foram distribuídas dez iscas de sardinha em cada área (cinco em residências e cinco em comércios) totalizando um esforço amostral de 960 iscas. Estas foram colocadas sobre o solo e expostas por aproximadamente 30 minutos, e, como locais para distribuição das mesmas, foram selecionados calçadas, jardins, garagens e muros. Adicionalmente, coletas diretas foram realizadas com o auxílio de cotonetes e frascos contendo álcool $70 \%$. As coletas tiveram um esforço amostral de aproximadamente 30 minutos por ambiente de coleta, totalizando 48 horas de amostragem. Como locais de coletas para este método foram selecionados paredes, calçadas, canteiros, muros e plantas.

Dada às diferenças encontradas nos imóveis amostrados (densidade e tipo de vegetação, ação antrópica, etc.), as coletas diretas foram realizadas preferencialmente sobre calçadas, sobre o solo ou sobre raízes, troncos e galhos de árvores.

Os espécimes coletados foram armazenados em frascos contendo álcool 70\%, devidamente etiquetados com os dados da coleta. Posteriormente, foram transportados para o Laboratório de Entomologia da Universidade Comunitária Regional de Chapecó Unochapecó, para triagem e identificação. A triagem do material se realizou pela separação em morfo-espécies, que posteriormente foram identificadas até gênero segundo chaves propostas por Fernández (2003) e até espécie através de consulta aos espécimes depositados no Museu Zoobotânico da Universidade Comunitária Regional de Chapecó - Unochapecó, e classificadas conforme Bolton (2003).

Todos os parâmetros das análises estatísticas foram obtidos a partir de equações aplicadas sobre o número de registros feitos para cada espécie. $\mathrm{O}$ índice 
de diversidade de Shannon \& Wiener (H') foi obtido seguindo a proposta de Magurran (1988) e calculado sobre os registros gerais das formigas capturadas.

Foram construídas curvas de acumulação de espécies observadas e estimadas (estimadores Jackknife 1 e Bootstrap). Estes indicadores foram obtidos através do programa EstimateS 6.0.b1 (Colwell, 2000).

\section{Resultados}

Foram registradas 2.981 formigas, das quais $1.552(52 \%)$ junto a residências e 1.429 (48 \%) junto a estabelecimentos comerciais (Tabela 1). Foram identificadas 67 espécies de formigas, distribuídas em 21 gêneros, 13 tribos e seis subfamílias: Myrmicinae (33 espécies; 49,2\%), Formicinae (17 espécies; 25,3\%), Dolichoderinae (10 espécies; 15\%), Ponerinae (4 espécies; 6\%), Pseudomyrmecinae (2 espécies; 3\%) e Ectatomminae (1 espécies; 1,5\%).

Dentre as espécies da subfamília Myrmicinae, destacaram-se Acromyrmex niger (F. Smith, 1858) Pheidole sp. 1 e Solenopsis sp. 5, registradas somente em ambientes comerciais. Apterostigma sp. 1, Pheidole sp. 9 e Solenopsis sp. 7 ocorreram somente em ambientes residenciais.

Em relação ao método de captura, as espécies da tribo Attini foram registradas somente manualmente, assim como Cephalotes sp. 1. As espécies registradas somente com iscas à base de sardinha foram Pheidole sp. 1, P. sp. 8, P. sp. 9, Solenopsis sp. 3, S. sp. 5, S. sp. 6, S. sp. 7 e $S$. sp. 8.

Para a subfamília Formicinae foram registradas 17 espécies, das quais 12 do gênero Camponotus. Camponotus sericeiventris Guérin-Méneville, 1838 e C. sp. 1 ocorreram somente em estabelecimentos comerciais e foram coletadas manualmente, já $C$. sp. 8 ocorreu apenas em residências sendo registrada com iscas.

Na subfamília Dolichoderinae, Linepithema humile e Linepithema sp. 4 ocorreram somente em ambientes comerciais, e $L$. sp. 1 ocorreu somente em residências. Quatro espécies desta subfamília, Dorymyrmex sp. 1, $D$. sp. 2, Linepithema sp. 1 e $L$. sp. 4, foram registradas somente em iscas de sardinha.

TABELA 1: Espécies de formigas coletadas junto a estabelecimentos comerciais (Com) e residenciais (Res), por método de coleta manual (Man) e sardinha (Sar) e por área estudada, na cidade de Xanxerê, Santa Catarina, no período de janeiro a dezembro de 2006.

\begin{tabular}{|c|c|c|c|c|c|c|c|c|}
\hline \multirow{2}{*}{ Táxon } & \multicolumn{8}{|c|}{ Número de registros } \\
\hline & Com & Res & Man & Sar & A1 & A2 & A3 & A4 \\
\hline \multicolumn{9}{|l|}{ Subfamília Dolichoderinae } \\
\hline \multicolumn{9}{|l|}{ Tribo Dolichoderini } \\
\hline Dorymyrmex sp. 1 & 1 & - & - & 1 & 1 & - & - & - \\
\hline Dorymyrmex sp. 2 & 1 & - & - & 1 & - & - & - & 1 \\
\hline Dorymyrmex sp. 3 & 185 & 192 & 95 & 282 & 94 & 110 & 80 & 93 \\
\hline Linepithema humile (Mayr, 1868) & 2 & - & 1 & 1 & - & - & 1 & 1 \\
\hline Linepithema sp. 1 & - & 2 & - & 2 & - & 1 & 1 & - \\
\hline Linepithema sp. 2 & 19 & 26 & 12 & 33 & 11 & 10 & 14 & 10 \\
\hline Linepithema sp. 3 & 19 & 21 & 14 & 26 & 7 & 12 & 9 & 12 \\
\hline Linepithema sp. 4 & 1 & - & - & 1 & - & - & 1 & - \\
\hline Tapinoma melanocephalum (Fabricius, 1793) & 28 & 34 & 22 & 40 & 19 & 22 & 10 & 11 \\
\hline Tapinoma sp. 1 & 2 & 6 & 3 & 5 & 2 & 4 & 2 & - \\
\hline
\end{tabular}




\section{Subfamília Ectatomminae}

Tribo Ectatommini

Gnamptogenys striatula Mayr, 1884

0

$\begin{array}{ll}3 & 3\end{array}$

Subfamília Formicinae

Tribo Camponotini

Camponotus crassus Mayr, 1862

Camponotus diversipalpus Santschi, 1922

Camponotus rufipes (Fabricius, 1775)

Camponotus sericeiventris (Guérin-Méneville, 1838)

Camponotus sp. 1

Camponotus sp. 2

Camponotus sp. 3

Camponotus sp. 4

Camponotus sp. 5

Camponotus sp. 6

Camponotus sp. 7

Camponotus sp. 8

\section{Tribo Plagiolepidini}

Myrmelachista sp. 1

Myrmelachista sp. 2

Paratrechina longicornis (Latreille, 1802)

Paratrechina sp. 1

$\begin{array}{cccccccc}57 & 54 & 42 & 69 & 38 & 17 & 32 & 24 \\ 1 & 1 & 2 & - & - & - & - & 2 \\ 55 & 64 & 51 & 68 & 23 & 29 & 26 & 41 \\ 1 & - & 1 & - & - & - & - & 1 \\ 1 & - & 1 & - & 1 & - & - & - \\ 21 & 32 & 26 & 27 & 11 & 13 & 9 & 20 \\ 2 & 5 & 4 & 3 & 2 & 1 & 3 & 1 \\ 4 & 16 & 9 & 11 & 1 & 3 & 11 & 5 \\ 56 & 67 & 49 & 74 & 30 & 33 & 35 & 25 \\ 7 & 7 & 4 & 10 & 4 & 4 & 4 & 2 \\ 37 & 32 & 23 & 46 & 12 & 20 & 16 & 21 \\ - & 1 & - & 1 & - & 1 & - & -\end{array}$

Paratrechina sp. 2

$\begin{array}{cccccccc}56 & 49 & 37 & 68 & 18 & 36 & 22 & 29 \\ - & 4 & 1 & 3 & 2 & 2 & - & - \\ 3 & 2 & 1 & 4 & 1 & 4 & - & - \\ 46 & 56 & 31 & 71 & 36 & 25 & 28 & 13 \\ 2 & - & 1 & 1 & - & 2 & - & -\end{array}$

Subfamília Myrmicinae

\section{Tribo Attini}

Acromyrmex niger (F. Smith, 1858)

Acromyrmex subterraneus (Forel, 1893)

Apterostigma sp. 1

Atta sexdens (Linnaeus, 1758)

Mycocepurus goeldii (Forel, 1893)

Mycocepurus sp. 1

$\begin{array}{cccccccc}4 & - & 4 & - & 1 & 2 & - & 1 \\ 13 & 18 & 31 & - & 5 & 7 & 14 & 5 \\ - & 1 & 1 & - & - & - & - & 1 \\ 72 & 64 & 136 & - & 32 & 31 & 39 & 34 \\ 27 & 35 & 62 & - & 10 & 21 & 13 & 18 \\ 2 & 1 & 3 & - & - & - & 3 & - \\ & & & & & & & \\ 5 & 3 & 2 & 6 & 4 & 1 & 1 & 2 \\ & & & & & & & \\ 7 & 14 & 10 & 11 & 1 & 11 & 9 & - \\ - & 1 & 1 & - & - & - & - & 1 \\ & & & & & & & \\ 7 & 9 & 5 & 11 & 4 & 1 & 3 & 8 \\ 10 & 14 & 9 & 15 & 11 & 1 & 5 & 7 \\ 29 & 33 & 17 & 45 & 16 & 25 & 14 & 7 \\ 4 & 7 & 5 & 6 & 3 & 4 & 1 & 3\end{array}$

Tribo Blepharidattini

Wasmania auropunctata Roger, 1863

Tribo Cephalotini

Cephalotes pusillus (Klug, 1824)

Cephalotes sp. 1

Tribo Crematogastrini

Crematogaster acuta (Fabricius, 1804)

Crematogaster sp. 1

Crematogaster sp. 2

Crematogaster sp. 3 
Tribo Myrmicini

Pogonomyrmex naegelii Forel, 1878

$\begin{array}{cccccccc}91 & 64 & 51 & 104 & 52 & 43 & 24 & 36 \\ 4 & 12 & 6 & 10 & 5 & 1 & 5 & 5 \\ & & & & & & & \\ 2 & - & - & 2 & 2 & - & - & - \\ 121 & 156 & 66 & 211 & 68 & 50 & 81 & 78 \\ 20 & 15 & 5 & 30 & 7 & 7 & 13 & 8 \\ 21 & 32 & 13 & 40 & 8 & 13 & 17 & 15 \\ 87 & 101 & 52 & 136 & 47 & 60 & 43 & 38 \\ 25 & 19 & 17 & 27 & 2 & 10 & 15 & 17 \\ 8 & 4 & 2 & 10 & 1 & - & 5 & 6 \\ 1 & 2 & - & 3 & - & 1 & 1 & 1 \\ - & 1 & - & 1 & - & - & - & 1\end{array}$

Tribo Solenopsidini

Solenopsis saevissima (F. Smith, 1855)

$\begin{array}{cccccccc}202 & 216 & 114 & 304 & 93 & 110 & 119 & 96 \\ 16 & 10 & 7 & 19 & 6 & 5 & 9 & 6 \\ 25 & 15 & 10 & 30 & 5 & 11 & 12 & 12 \\ - & 2 & - & 2 & - & - & 2 & - \\ 2 & 1 & 2 & 1 & 1 & - & - & 2 \\ 1 & - & - & 1 & - & 1 & - & - \\ 1 & 1 & - & 2 & - & - & - & 2 \\ - & 1 & - & 1 & - & 1 & - & - \\ - & 1 & - & 1 & 1 & - & - & -\end{array}$

Solenopsis sp. 1

Solenopsis sp. 2

Solenopsis sp. 3

Solenopsis sp. 4

Solenopsis sp. 5

Solenopsis sp. 6

Solenopsis sp. 7

Solenopsis sp. 8

Subfamília Ponerinae

Tribo Ponerini

Hypoponera sp. 1

Hypoponera sp. 2

Pachycondyla harpax (Fabricius, 1804)

12

Pachycondyla striata Fr. Smith, 1858

\begin{tabular}{cccccccc}
1 & 2 & 3 & - & 2 & 1 & - & - \\
- & 1 & - & 1 & - & 1 & - & - \\
- & 3 & 1 & 2 & 1 & 1 & 1 & - \\
6 & 8 & 4 & 10 & 4 & 3 & 4 & 3 \\
& & & & & & & \\
- & 3 & 3 & - & 1 & 1 & - & 1 \\
8 & 8 & 9 & 7 & 6 & 2 & 2 & 6 \\
1429 & 1552 & 1084 & 1897 & 713 & 775 & 760 & 733 \\
\hline
\end{tabular}

Subfamília Pseudomyrmecinae

\section{Tribo Pseudomyrmecini}

Pseudomyrmex flavidulus (Fr. Smith, 1858)

Pseudomyrmex gracilis (Fabricius, 1804)

Total de registros

Os valores estimados de riqueza (Jackknife 1 e Bootstrap) para a fauna registrada no ambiente urbano da cidade (Figura 1), mostram que a riqueza de espécies observada se aproxima da esperada e que as curvas são assintóticas.
Quando verificada a riqueza entre as áreas, foi possível perceber que a encontrada (Sobs) se aproxima da estimada pelo estimador Bootstrap. Já o estimador Jackknife 1 encontrou um valor total de 83,29 sendo 24,3\% maior que o observado (Tabela 2). 


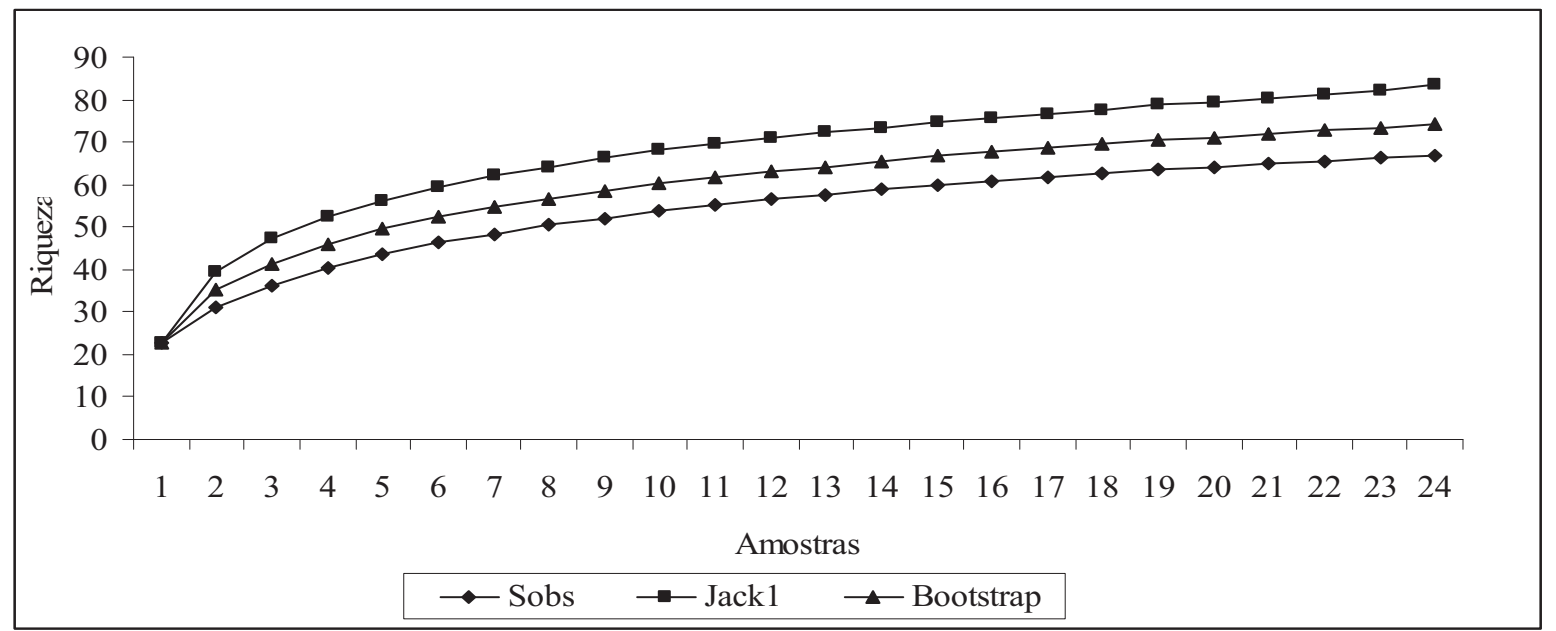

FIGURA 1: Riqueza de formigas observada (Sobs) e estimada (Jack 1 e Bootstrap) na cidade de Xanxerê, Santa Catarina, no período de janeiro a dezembro de 2006.

TABELA 2: Índices de riqueza observada (Sobs) e estimada (Jackknife 1 e Bootstrap) para as áreas da cidade de Xanxerê, Santa Catarina, no período de janeiro a dezembro de 2006.

\begin{tabular}{cccc}
\hline & Sobs & Jackknife 1 & Bootstrap \\
\hline Área 1 & 47 & 61,38 & 53,28 \\
Área 2 & 47 & 63,29 & 53,9 \\
Área 3 & 42 & 49,67 & 45,71 \\
Área 4 & 46 & 58,46 & 51,57 \\
Geral & 67 & 83,29 & 74,12 \\
\hline
\end{tabular}

\section{Discussão}

A associação de formigas com o homem vem sendo evidenciada há muito tempo (Campos-Farinha et al., 2002), e é intensificada ao passo que o processo de urbanização avança, gerando condições propícias à sobrevivência de formigas sinantrópicas (Silva e Loeck, 1999). Estudos recentes reforçam essa afirmação, à medida que documentam novos registros de formigas associadas à organismos patogênicos em instituições de ensino e em hospitais (Ferraboli et al., 2007; Rodovalho et al., 2007), e de formigas que atacam espécies florestais exóticas e nativas usadas no paisagismo urbano (Anjos et al., 2008).
A maioria das espécies que causam danos aos humanos é exótica, introduzidas acidentalmente através do comércio entre países. Quando uma espécie exótica é introduzida em um ambiente, acaba por competir com as espécies nativas pelos recursos alimentares e pelo habitat. Nesta pesquisa, encontramos duas espécies exóticas, T. melanocephalum e P. longicornis, que foram registradas em ambos os ambientes amostrados (residencial e comercial).

No entanto, não são apenas as espécies exóticas que podem causar danos quando encontradas em ambientes urbanos. Segundo Bueno e Campos-Farinha (1999), muitas espécies do gênero Camponotus, nativas das Américas, são capazes de fazer associações com o homem e, quando encontradas em residências e estabelecimentos comerciais, podem indicar que o imóvel possui deficiências estruturais. Neste trabalho, o gênero Camponotus apresentou a maior riqueza de espécies $(17,91 \%)$ e foi encontrado abundantemente em ambos os ambientes de coleta, o que comprova sua associação com o homem. Camponotus rufipes, que apresentou 7,98\% dos registros, é característica de ambientes perturbados e abertos (Morini et al., 2003).

Muitas espécies do gênero Paratrechina foram espalhadas pelo mundo através do comércio, dentre elas $P$. longicornis que, segundo Bueno e CamposFarinha (1999), é considerada como uma das espécies exóticas mais importantes. Esta espécie tem sido 
encontrada associada a ambientes urbanos no Brasil, tanto em residências e comércios quanto em ambientes hospitalares (Bueno e Campos-Farinha, 1999; Moreira et al., 2005; Oliveira e Campos-Farinha, 2005; Costa et al., 2006; Lise et al., 2006; Soares et al., 2006; Farneda et al., 2007), onde causa grande incômodo e se comporta como vetor mecânico de organismos patogênicos. Esta espécie teve baixo número de registros $(0,17 \%)$ nesta pesquisa, mas em pesquisa semelhante realizada por Farneda et al. (2007) na cidade de Pinhalzinho, também na região oeste do Estado, apresentou 9,6\% dos registros.

As espécies dos gêneros Dorymyrmex e Linepithema caracterizam-se por serem onívoras, visitarem iscas e apresentarem um comportamento oportunista evitando interações agressivas com outras espécies. Ainda, as espécies destes gêneros apresentam comportamento de recrutamento massivo (Silvestre e Silva, 2001). No interior de construções, L. humile é uma das espécies mais freqüentes (Silva e Loeck, 1999), diferentemente do encontrado em nosso estudo (apenas 0,07\% dos registros).

Piva e Campos-Farinha (1999) afirmam que $S$. saevissima apesar de não ser considerada uma praga, possui grande atração por ambientes perturbados. Silva e Loeck (1999) afirmam que esta espécie é mais freqüente no interior de construções e em residências com problemas de conservação. A mesma também já foi registrada em ambientes hospitalares e sua presença foi constante (Lise et al., 2006). Em contrapartida, Piva e Campos-Farinha (1999), em trabalho realizado em uma vila da cidade de São Paulo, apontam que $S$. saevissima só foi registrada em áreas externas de residências, com pouca ocorrência. No presente trabalho, a espécie foi registrada por ambos os métodos de coleta e em ambos os ambientes, tendo $14,02 \%$ de registros.

O gênero Pheidole apresenta entre 10 e 15 espécies que podem ser consideradas pragas urbanas. A presença destas espécies em ambientes residenciais, comerciais ou hospitalares, pode indicar deficiências estruturais (Bueno e Campos-Farinha, 1999), fato também comprovado por Silva e Loeck (1999). A maioria das espécies deste gênero foi registrada em ambos os métodos de captura e ambientes, apresentando elevado número de registros (Tabela 1).
As espécies da tribo Attini, neste estudo, foram coletadas manualmente e apresentaram $20,63 \%$ do número de registros. São cultivadoras de fungos sobre material vegetal em decomposição, coletando folhas frescas, pedaços de artrópodos, frutos ou fezes de animais para a produção dessas matérias (Silvestre e Silva, 2001). As espécies dos gêneros Atta e Acromyrmex constituem os herbívoros dominantes da região neotropical, consumindo muito mais plantas que qualquer outro grupo taxonômico comparável (Diehl-Fleig, 1995). Em recente trabalho (Anjos et al., 2008), constatouse ataques de $A$. subterraneus e A. niger à Latania commersonii J. F. Gmel., uma palmácea amplamente usada no paisagismo urbano, e ataques de $A$. niger à Araucaria angustifolia (Bertol.). Resultados como esses ressaltam a importância de conhecer a biologia das formigas que vivem em ambientes urbanos.

As espécies dos gêneros Cephalotes, Crematogaster, Pseudomyrmex e Myrmelachista caracterizam-se por nidificarem principalmente sobre a vegetação e apresentarem dieta onívora (Silvestre e Silva, 2001). O significativo número de registros das espécies desses gêneros certamente está relacionado à quantidade de vegetação presente na área urbana da cidade. Estas espécies foram registradas principalmente em ambientes residenciais, onde a arborização é maior, o que permite a nidificação de algumas espécies de formigas arborícolas. As espécies de Myrmelachista apresentam atividade exclusivamente na vegetação, e segundo Silvestre e Silva (2001) podem ser boas indicadoras de áreas que estão sendo recuperadas. Dessa forma, os registros de Myrmelachista nesse trabalho possivelmente foram obtidos em amostragens de áreas residenciais ou comerciais mais densamente florestadas, ao usarmos iscas ou coletas diretas junto à vegetação.

Segundo Agosti et al. (2000), o tempo necessário para a atração de formigas em iscas de sardinha é de 60 a 90 minutos. Nesse trabalho, as iscas foram deixadas por aproximadamente 30 minutos. Apesar do tempo de exposição das iscas ter sido inferior ao recomendado, os resultados obtidos evidenciaram uma riqueza de formigas significativa para a cidade. Ainda, pode-se concluir através destes resultados que as coletas manuais foram importantes e complementares às iscas, uma 
vez que 19,4\% das espécies registradas não visitaram iscas.

O perímetro urbano da cidade de Xanxerê apresentou uma diversidade H' de 3,17. Assim, pode-se inferir que a diversidade de formigas neste ambiente é tão rica quanto à encontrada no trabalho de Farneda et al. (2007), que encontrou uma diversidade H' de 3,09 no perímetro urbano da cidade de Pinhalzinho, Santa Catarina.

A partir da avaliação das formigas urbanas da cidade, foi possível verificar o registro de espécies que podem causar incômodo quando presentes em ambientes urbanos, como é o caso das formigas cultivadoras de fungos (Attini), das espécies exóticas, das espécies nativas do gênero Camponotus, e outras espécies características de ambientes perturbados. Foram também registradas espécies especialistas de habitat, como as dos gêneros Cephalotes, Myrmelachista e Pseudomyrmex, caracterizadas por se associarem a vegetação.

Para serem evitados incômodos causados por espécies generalistas, recomenda-se manter o interior das residências e estabelecimentos comerciais sempre limpos, assim como manter o jardim dos mesmos sem acúmulos de lixos ou entulhos. Dessa forma evita-se a nidificação dessas formigas em suas proximidades. Por outro lado, para que espécies especialistas de habitat não sejam extintas localmente, haja vista que possuem um importante papel ecológico no local onde ocorrem naturalmente, é necessário manter áreas arborizadas no perímetro urbano com espécies da vegetação nativa.

\section{Agradecimentos}

Agradecemos à Universidade Comunitária Regional de Chapecó - Unochapecó, pelo auxílio com materiais e autorização de trabalho no Laboratório de Entomologia; à Andressa Iop, Eloíza Iop e Sidiane Inês Spuldaro Padilha, pelo auxílio nas coletas; à Débora Balem, pelas considerações no abstract; ao Dr. Rogério R. Silva pelas valiosas sugestões numa versão preliminar do manuscrito, e aos moradores e comerciantes da cidade de Xanxerê, por permitirem as coletas na abrangência de seus domínios.

\section{Referências}

Agosti, D.; Majer, J. D.; Alonso, L. E.; Schultz, T. R. 2000. Ants: Standard methods for measuring and monitoring biodiversity. Smithsonian Institution Press, Washington, USA, 280pp.

Agosti, D.; Jonhson, N. F. 2008. Editors. Antbase. World wide web electronic publication. Antbase. Org, version (05/2005). Disponivel em $<\mathrm{http}$ ://www.antbase.org $>$. Acesso em 22 de abril de 2008.

Anjos, N. dos; Arnhold, A.; Corrêa, G. V. V.; Stumpf, K. 2008. Árvores e formigas cortadeiras (Hymenoptera: Formicidae) em Viçosa, Minas Gerais. Revistra Trópica - Ciências Agrárias e Biológicas, 1 (2): 11-16.

Bolton, B. 2003. Synopsis and classification of Formicidae. Memoirs of the American Entomological Institute, Gainesville, USA, 370pp.

Bueno, O. C.; Campos-Farinha, A. E. C. 1999. As formigas domésticas. In Mariconi, F. A. M. (Ed.). Insetos e outros invasores de residências. FEALQ, Piracicaba, Brasil, p.135-180.

Campos-Farinha, A. E. C.; Bueno, O. C.; Campos, M. G. C.; Kato, L. M. 2002. As formigas urbanas no Brasil: retrospecto. Biológico, 62 (2): 129-133.

Colwell, R. K. 2000. Estimates: Statistical estimations of species richness and shared species from samples. Version 6.0b1. User's guide and application published at $<$ http://viceroy.eeb.uconn.edu/ estimates $>$.

Costa, S. B. D; Pelli, A.; Carvalho, G. P. de.; Oliveira, A. G.; Silva, P. R. da.; Teixeira, M. M.; Martins, E.; Terra, A. P. S.; Resende, E. M.; Oliveira, C. da. C. H. B. de.; Morais, C. A. de. 2006. Formigas como vetores mecânicos de microorganismos no Hospital Escola da Universidade Federal do Triângulo Mineiro. Revista da Sociedade Brasileira de Medicina Tropical, 39 (6): 527-529.

Diehl-Fleig, E. 1995. Formigas: Organização social e ecologia comportamental. Ed. Unisinos, São Leopoldo, Brasil, 168pp.

Ferraboli, R.; Nakano, V.; Leoni, L. A. B.; Andreska, C.; Latorre, D. C. P.; Almeida, G. C. de; Leão, I. N.; Rodrigues, P. O.; Silva, A. P. da. 2007. Formigas (hymenoptera: formicidae) como hospedeiros paratênicos de bactérias e parasitas. Integração, 51: 353-356.

Farneda, F. Z.; Lutinski, J. A.; Garcia, F. R. M. 2007. Comunidade de formigas (Hymenoptera: Formicidae) na área urbana do município de Pinhalzinho, Santa Catarina, Brasil. Revista Ciências Ambientais, 1 (2): 53-66.

Fernández, F. 2003. Introducción a las hormigas de la región neotropical. Instituto de Investigación de Recursos Biológicos Alexander von Humboldt, Bogotá, Colombia, 418pp.

Fowler, H. G.; Bernardi, O. C.; Sadatsube, T.; Montelli, A. C. 1993. Ants as potencial vectors of pathogens in Brazil hospitals in the State of São Paulo, Brazil. Insecta Science and its Application, 14 (3): $367-370$.

IBGE - Instituto Brasileiro de Geografia e Estatística. 2008. Disponível em <http://www.ibge.gov.br/cidadesat/default.php>. Acesso em 09 de abril de 2008.

Lise, F.; Garcia, F. R. M.; Lutinski, J. A. 2006. Association of ants (Hymenoptera: Formicidae) with bacteria in hospitals in the State of Santa Catarina. Revista da Sociedade Brasileira de Medicina Tropical, 39 (6): 523-526. 
Magurran, A. 1988. Ecological diversity and its measurement. Princeton University Press, New Jersey, USA, 75pp.

Moreira, D. D. O.; Morais, V.; Vieira-da-Mota, O.; Campos-Farinha, A. E.; Tonhasca Jr., A. 2005. Ants as carriers of antibiotic-resistant bacteria in hospitals. Neotropical Entomology, 34 (6): 999-1006.

Morini, M. S. C.; Silva, R. R.; Kato, L. 2003. Non-specific interaction between ants (Hymenoptera: Formicidae) and fruits of Syagrus romanzoffiana (Arecaceae) in an area of the Brasilian atlantic forest. Sociobiology, 42 (3): 663-673.

Oliveira M. F.; Campos-Farinha, A. E. 2005. Formigas urbanas do município de Maringá, PR, e suas implicações. Arquivos do Instituto Biológico, 72 (1): 33-39.

Piva, A.; Campos-Farinha, A. E. C. 1999. Estrutura de comunidade das formigas urbanas do bairro da Vila Mariana na cidade de São Paulo. Naturalia, 24: 115-117.

Rodovalho, C. M.; Santos, A. L.; Marcolino, M. T.; Bonetti, A. M.; Brandeburgo, M. A. M. 2007. Urban ants and transportation of nosocomial bacteria. Neotropical Entomology, 36 (3): 454-458.

Silva, E. J. E.; Loeck, A. E. 1999. Ocorrência de formigas domiciliares (Hymenoptera: Formicidae) em Pelotas, RS. Revista Brasileira de Agrociência, 5 (3): 220-224.
Silva, R. R. 1999. Formigas (Hymenoptera: Formicidae) do oeste de Santa Catarina: histórico das coletas e lista atualizada das espécies do Estado de Santa Catarina. Biotemas, 12 (2): 75-100.

Silva, R. R.; Silvestre, R. 2000. Diversidade de formigas (Hymenoptera: Formicidae) em Seara, oeste de Santa Catarina. Biotemas, 13 (2): 85-105.

Silvestre, R.; Silva, R. R. da. 2001. Guildas de formigas da Estação Ecológica Jataí, Luiz Antônio - SP. Sugestões para aplicação do modelo de guildas como bio-indicadores ambientais. Biotemas, 14 (1): 37-69.

Soares, S. S.; Almeida, L. O.; Gonçalves, C. A.; Marcolino, M. T.; Bonetti, A. M. 2006. Levantamento da diversidade de formigas (Hymenoptera: Formicidae) na região urbana de Uberlândia, MG. Neotropical Entomology, 35 (3): 324-328.

Statsoft, INC. 2001. Statistica (data analysis software system), version 6. www.statsoft.com.

Zarzuela, M. F. M.; Ribeiro, M. C. C.; Campos-Farinha, A. E. C. 2002. Distribuição de formigas urbanas em um hospital da região sudeste do Brasil. Arquivos do Instituto Biológico, 69 (1): 85-87. 